Bulgarian Academy of Sciences. Space Research and Technology Institute. Aerospace Research in Bulgaria. 30, 2018, Sofia

DOI: https://doi.org/10.3897/arb.v30.e04

\title{
SOME SPECIFICS OF THE DISTRIBUTION OF ELECTROMAGNETIC POLLUTION ON THE TERRITORY OF SOFIA MUNICIPALITY
}

\author{
Teodora Andreeva-Nesheva ${ }^{1}$, Dimitar Teodossiev ${ }^{1}$, Iliya Iliev ${ }^{2}$ \\ ${ }^{1}$ Space Research and Technology Institute - Bulgarian Academy of Sciences \\ ${ }^{2}$ Technical University of Sofia, Faculty of Telecommunications \\ e-mail: teoandreeval@gmail.com
}

\begin{abstract}
Some results from measurements of electromagnetic radiation in the frequency range between $110 \mathrm{kHz}$ and $7 \mathrm{GHz}$ on the territory of Sofia Municipality are presented and the observed deviations of the measured levels from the adopted maximal allowed values are discussed. The development of methods for evaluation and optimization of electromagnetic emissions in urbanized environments is suggested and justified, as well as the construction of a monitoring and control system for electromagnetic radiation and background noise in strongly urbanized territories, such as Sofia Municipality.
\end{abstract}

\section{Introduction}

One of the environmental energy pollution factors are electromagnetic fields. As a result of the exclusively wide application of electromagnetic energy in various human activity domains, the available sources of the Earth's natural electric and magnetic fields, atmospheric electricity and Galactic and solar radio radiation are supplemented by electromagnetic fields of artificial origin. It is a fact that, in a number of cases, their level exceeds significantly the level of electromagnetic fields originating from natural sources.

In technical literature, serious concern for the increase of electromagnetic radiation (EMR) and from there - of the total background noise (BN) is expressed. Various EMR man-induced sources exist - TV and radio-transmitters, radar antennae, basic mobile operator stations and more. Recent scientific research shows that the levels of EMR and BN are already reaching sufficiently high values to cause disturbances in the electromagnetic compatibility of the available radio equipment, mostly in urban environment, where their concentration is highest. This calls for the need to apply specific methods to measure, monitor and forecast the increase of EMR and $\mathrm{BN}$.

In a strongly developed urban environment where total $\mathrm{BN}$ is increased, the so-called "hot points" or "hot areas" may appear where the electromagnetic field 
level exceeds the health norms set by regulation. This requires developing effective and reliable methods to forecast the EM circumstances in the vicinity of the typical communication sources and to assess the compliance with EMR admissible level norms.

The measurement, continuous monitoring, composing of a database and evaluation of the parameters of the electromagnetic fields in urban environment are an important aspect of EMR to achieve healthy living environment. Although no direct scientific evidence of any relation between EM fields and human diseases is available, it is necessary to undertake all precautionary measures against the uncontrolled increase of EMR levels.

To assess the actual circumstances and the characteristic features of the distribution of EMR in strongly urbanized urban environment, it is required to perform a series of preliminary measurements in various points of the territory of Sofia Municipality (SM), various 24-hour intervals, various meteorological circumstances and various distances to the irradiating antenna [1-8].

\section{Objective of the study}

The major objective of this study is to present and analyse some specifics in the distribution of EMR levels in the districts of SM, which is characterized by different concentration of ground-based sources (TV and radio-transmitters, radar antennae, basic mobile operator stations and more), operation in the frequency range of $680 \div 2500 \mathrm{MHz}$, and also by different urbanization degree and relief. The presented analysis of the results from the carried out measurements in different points of the territory of SM featuring different urbanization degree was made while implementing the first stage of Contract No. ДН 07/19/2016 with the Scientific Research Fund, "Methods for Evaluation and Optimization of Electromagnetic Radiation in Urbanized Environments".

\section{Methodology}

The study is based on the experience and the developed methods as a result of the successfully concluded European Project under the SEE-ERA-NET Programme "Development of Method and Strategy for Monitoring of Electromagnetic Pollution in the West Balkan Region", implemented by SRTI-BAS as a leading organization with partners from Republic of North Macedonia, Slovenia, and Croatia in 2009 [2].

The measurements were performed in accordance with Regulation No. 9 from 1991 of the Ministry of Health applying a control method according to the Bulgarian State Standard (BSS) 17137-90 (БДС 17137-90). 


\section{Used equipment}

Two sets of dedicated mobile equipment were used. The first one is "SPECTRAN", produce of the German company AARONIA AG, including unit "SPECTRAN HF 6060 for measurement in the range between $1 \mathrm{MHz}$ and $7 \mathrm{GHz}$, with directed antenna of the HyperLOG 6080 type. The results from the measurements are visualized in real time and are recorded on HP Compaq 6720s laptop, with installed software of the producing company, providing to carry out adjustments, measurements, visualization and storage of the results.

The second device is the autonomous station NARDA AMB 8057-03 intended for electromagnetic monitoring of the environment in the frequency range from $110 \mathrm{kHz}$ to $7 \mathrm{GHz}$, which provides for continuous autonomous control of electromagnetic radiation, even in points hardly accessible for observation. Data is transferred automatically to the server hosting the database, whereas possibility for remote control of the device is also provided. The results from the measurements are stored in dedicated database containing information about EMR characteristics, distribution by frequency and location (coordinates of the measurement points in geographic information system - GIS).

The mobile equipment Narda AMB 8057-3 provides possibilities for visualization and reviewing of the information from the measurements for a chosen interval of time, date, week or twenty-four-hour period for the entire frequency range $(110 \mathrm{kHz} \div 7 \mathrm{GHz})$, a chosen subinterval of the frequency range $(110 \mathrm{kHz} \div 7 \mathrm{GHz})$, peak values or averaged value for a definite frequency, chosen time interval of the twenty-four-hour period, for observation of fine effects in the distribution of the irradiated power for a given frequency, whereas the maximal admissible radiation level for this frequency is marked by a red line.

Both devices are furnished with dedicated software for data storage, visualization and processing and with a solar panel providing power supply when operating in autonomous mode, as well as the possibility to transmit the measured data to a dedicated server located at a distance from the measurement point.

\section{Experimental results}

The results from the measurements of EMR intensity at two characteristic points of SM are presented and analysed. One is located in the ideal centre of Sofia, a building of SM located in 5, Serdika Street, and the other one is located in Bankya District. The first measurement point is packed with a lot of administrative buildings and radiating antennae, accordingly, and the other point is characterised by low construction and quite diverse relief, but also by a basic mobile operator station in its immediate vicinity.

Measurements on the territory of Bankya District, in a private house, in two premises on the second floor of the house, located about $22 \mathrm{~m}$ away from another 
house, with antennae of a basic mobile operator station assembled on the roof. The measurements were carried out by mobile equipment "SPECTRAN HF 6060", in the range of $700 \div 2500 \mathrm{MHz}$, using antenna of the HyperLOG 7060 type, over the time interval between 10:30 and 11:30 h a.m., in October, in dry weather and air temperature of about $25^{\circ} \mathrm{C}$.

The results from the measurements of the intensity of the energy flow in the premises - sitting room on the second floor of the house located in 10, Radost Street, are presented on the following graph which shows the measured values in microwatts per square centimetre for the time interval between 11:17 and 11:35 h a.m., i.e. measurement in the course of 18 minutes.
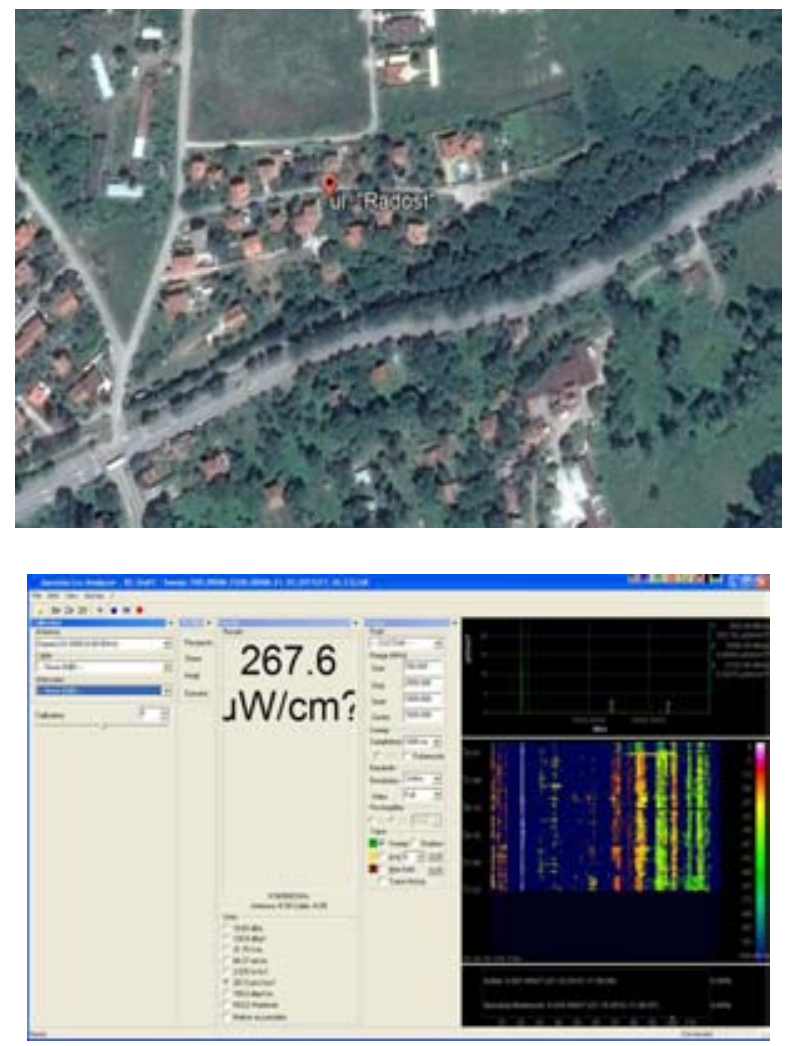

Fig. 1. Satellite photo of the territory of Bankya District, where the measurements of the density of EMR energy flow were carried out and the results of the measurements on a screenshot of the laptop to which the measurement device "SPECTRAN HF 6060" was connected 
The results on the laptop's screen show the maximal levels of the irradiated power for the individual frequencies during the measurements. Maximum measured EMR levels are of about $267 \mu \mathrm{W} / \mathrm{cm}^{2}$ at frequency of $943 \mathrm{MHz}$ are observed.

The next graph, Fig. 2, shows the averaged values of the results from the measured density of the energy flow in the premises - sitting room on the second floor of the house, in $\mu \mathrm{W} / \mathrm{cm}^{2}$ over time interval between 11:17 and 11:35 $\mathrm{h}$ a.m.

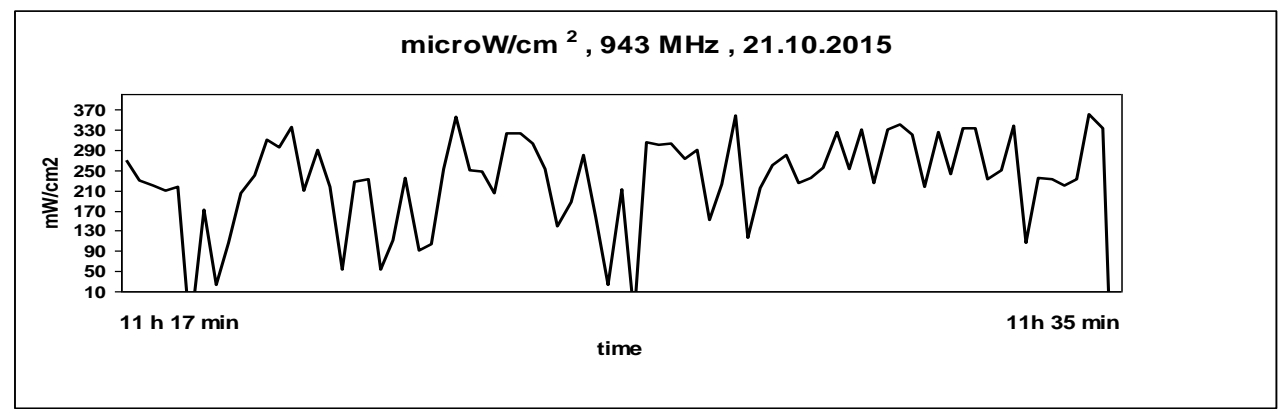

Fig. 2. Averaged values of the results from measuring the density of EMR energy flow over this time period

It may be seen that the average level of irradiated power is about $244.22 \mu \mathrm{W} / \mathrm{cm}^{2}$, which is more than 20 times greater than the norm allowed by standard, $10 \mu \mathrm{W} / \mathrm{cm}^{2}$. Of this order and a little bit greater were also the values measured on the terrace of the same floor. This point is located about 22-25 meters off the basic station's irradiating antennae, measured along a direct line.

Measurements in the ideal centre of Sofia, in the building of SM in 5, Serdika Street, in front of the office of Sofia's Chief Architect.

Using the mobile equipment Narda AMB 8057-3, which provides for continuous autonomous control of electromagnetic radiation, long-lasting uninterrupted measurements of EMR from various sources in the frequency range of $110 \mathrm{kHz} \div 7 \mathrm{GHz}$ were carried out, including on business days and holidays, for a period of nearly four months (March - June). Date transmission to the place where the server was located, its recording and storage in the database was performed automatically. The results from the measurements in the database contain information about the characteristics, the distribution by frequency and the location of the measurement point (coordinates of the measurement points in GIS).

Some results from EMR measurements are shown on the next Fig. 3 which illustrates clearly the characteristic course of the changes in EMR intensity over the entire frequency range depending on the intensity of the irradiating antenna and the number of used mobile communication units. 

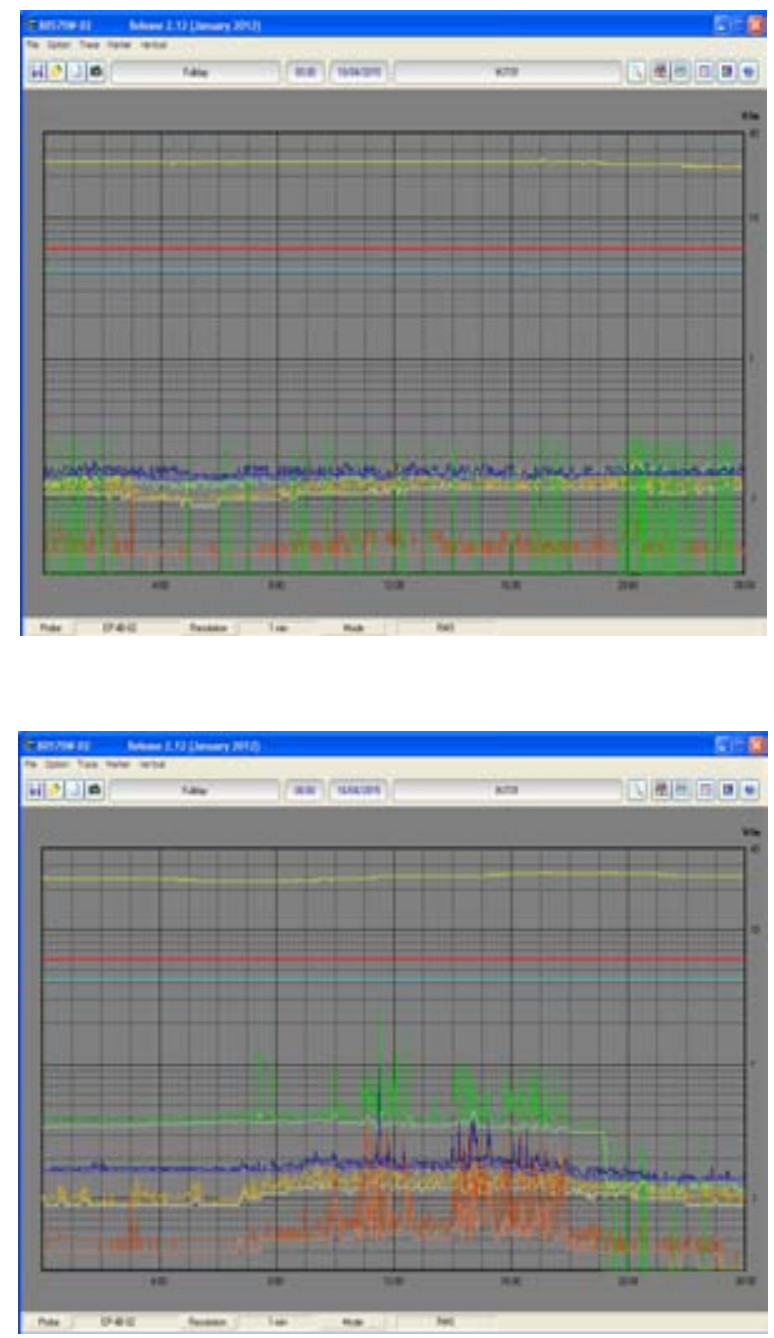

Fig. 3. Results from the measurements carried out by the autonomous measurement device Narda AMB 8057-3. Data from 24-hour continuous measurements for one holiday and one normal business day is presented. 
The measured values of electromagnetic fields in the range $110 \mathrm{kHz} \div 7 \mathrm{GHz}$ for HOLIDAYS feature smooth constant course for all frequencies, much below the admissible field value of $6 \mathrm{~V} / \mathrm{m}$, while in the time period between 07:00 $\mathrm{h}$ a.m. and 06:00 h p.m. for BUSINESS DAYS, the expected course is observed, with increased EMR intensity in the intervals between 02:00 and 06:00 h p.m. The analysis of the data shows that, irrespective of the increased EMR levels for business days, no cases of exceeding or even nearing the maximal allowed norm for this frequency range are observed.

\section{Conclusion}

The urbanization degree of a given territory, the number of irradiation antennae, their power and location has material influence on EMR intensity and BN level. The cases of exceeding the maximal allowed norms according to BSS in some individual points of SM are rather an exception. The primary reasons for available single cases of exceeding the allowed norms may be discrepancies during the approval of the city regulation plan for the respective district and lack of coordination between the construction supervision bodies and the bodies controlling the assembly of new irradiating antennae.

These results and conclusions prove the need of development of EMR evaluation and optimization methods in urbanized environments. Based on this, it is necessary to undertake construction of a System for Monitoring and Control of Electromagnetic Pollution on the Territory of SM using autonomous stations of the type of Narda AMB 8057-3, connected to a GIS. This system will provide data to State and Municipal bodies enabling to control and manage EMR and BN, as well to inform the citizens about environmental EMR.

The basic components of this System for Monitoring and Control of Electromagnetic Pollution on the Territory of SM aiming to manage the information about environment, to plan and develop infrastructure and to provide for sustainable development of Sofia include:

- Sufficient number of available ground-based stations of the type of the mobile equipment NARDA AMB 8057, located in different points of SM (one for each metropolitan district may be envisaged), operating in a connected mode and measuring within the frequency range of $10 \mathrm{~Hz} \div 7 \mathrm{GHz}$;

- The data from the antennae shall be recorded automatically on a special server in digital form and an option for their visualization for any chosen time interval in the required form shall be provided;

- A dedicated database referred to the GIS, with definite modes and access levels intended to inform the public, as well as to be used by the Municipal and State bodies during the preparation, planning and taking of different managerial decisions; 
- Composing of maps of SM territory, referred to GIS, on the overall and by individual districts, presenting the distribution of EMR and BN levels over a definite period, using dedicated software developed for the purpose;

- Composing of maps of SM territory, referred to GIS, with forecast EMR levels, based on recorded data about the location and the powers irradiated by the SM-licensed antennae of firms and State organizations using the dedicated software;

- Establishment of a control centre furnished with data collection server; management of the station network; database in GIS system; preparation of information for the population; preparation of information and analyses on the request of Municipal and State bodies; provision of information about EMR levels to SM for a remuneration on the request of external clients.

- Preparation for application of a version of this system for the needs of other Municipalities on the territory of the country.

The System for Monitoring and Control of Electromagnetic Pollution on the Territory of SM should provide for development, adaptation and superstructuring, accounting for future recommendations and requirements of the EU and other international organizations, such as the World Health Organization (WHO), the International Commission on Non-Ionizing Radiation Protection (ICNIRP).

Appreciation: The authors pay their gratitude to the Scientific Research Fund for the provided financial support for this article prepared while implementing Contract No. ДН 07/19/2016.

\section{References}

1. Contract № ДН 07/19/2016, Project „Methods for Evaluation and Optimization of Electromagnetic Radiations in Urban Areas".

2. Getsov, P., D. Teodosiev, E. Roumenina, M. Israel, G. Mardirossian, G. Sotirov, S. Velkoski, P. Gajesek, D. Simunic, and K. Iliev. Development of a Strategy and Methods for Monitoring of Electromagnetic Pollution in the Environment of the Western Balkans, Scientific results of the SEE-ERA.NET Pilot Joint Call, Edited by J. Machačová, K. Rohsmann, 2009, 95-101. ISBN 978-3-200-01567-8

3. Baltiiski, P., I. Iliev, B. Kehaiov, V. Poulkov, and T. Cooklev. Long-Term Spectrum Monitoring with Big Data Analysis and Machine Learning for Cloud-Based Radio Access Networks, Wireless Personal Communications, Springer, http://link.springer.com/article/10.1007/s11277-015-2631-8, may 2015.

4. Manassas, A., A. Boursianis, and T. Samaras. Continuous electromagnetic radiation monitoring in the environment: analysis of the results in Greece, Radiation Protection Dosimetry, Oxford Journals, 2012.

5. Joyner, K., M. J. Van Wyk, and J. T. Rowley. National surveys of radiofrequency field strengths from radio base stations in Africa, Radiation Protection Dosimetry, 2014, $158,3,251-62$. 
6. Mahfouz, Z., L. Verloock, W. Joseph, and E. Tanghe, Comparison of temporal realistic Telecommunication base station exposure with worst-case estimation in two countries, Radiation Protection Dosimetry, 2013, 1-8.

7. Gotsis, A., N. Papanikolaou, and D. Komnakos. Non-ionizing electromagnetic radiation monitoring in Greece, Annals of telecommunications, Springer, February 2008, 63, $1-2,109-23$.

8. Röösli, M. et al.. Statistical analysis of personal radiofrequency electromagnetic field measurements with nondetects, Bioelectromagnetics, 2008, 29.

\section{НЯКОИ ОСОБЕНОСТИ В РАЗПРЕДЕЛЕНИЕТО НА ЕЛЕКТРОМАГНИТНОТО ЗАМЬРСЯВАНЕ НА ТЕРИТОРИЯТА НА СТОЛИЧНА ОБЩИНА}

\section{Т. Андреева-Нешева, Д. Теодосиев, И. Илиев}

\section{Резюме}

Представени са някои резултати от измервания на електромагнитните излъчвания, в честотния диапазон от $110 \mathrm{kHz}$ до $7 \mathrm{GHz}$ на територията на Столична община и са дискутирани наблюдавани отклонения в измерените нива, от приетите пределно допустими норми. Предложено и аргументирано е разработването на методи за оценка и оптимизиране на електромагнитните излъчвания в урбанизирани среди и изграждането на система за мониторинг на ЕМИ и ФШ в силно урбанизирани територии, като Столична община. 